\title{
Lack of Association between an XRCC1 Gene Polymorphism and Colorectal Cancer Survival in Thailand
}

\author{
Pallop Siewchaisakul ${ }^{1}$, Krittika Suwanrungruang ${ }^{2,5}$, Kirati Poomphakwaen ${ }^{3}$, \\ Surapon Wiangnon ${ }^{4,5}$, Supannee Promthet ${ }^{1,5 *}$
}

\begin{abstract}
Background: Colorectal cancer (CRC) is one of the most common causes of death worldwide and in Thailand. The X-ray repair cross-complementary protein 1 (XRCC1) is required for efficient DNA repair. The effects of this gene on survival in colorectal cancer remain controversial and have not been reported in Thailand. The aim of this study was to investigate the association of the $X R C C 1$ gene with survival of colorectal cancer patients in a Thai population. Materials and Methods: Data and blood samples were collected from 255 newly diagnosed and pathologically confirmed CRC patients who were recruited during the period 2002 to 2006 and whose vital status was followed up until 31 October, 2014. Real-time PCR-HRM was used for genotype identification. The Kaplan-Meier method, the log-rank test, and Cox proportional hazard regression were used to estimate cumulative survival curves and compare various survival distributions and adjusted hazard ratios. Results: Most of the cases were males, and the median age was 55 years. The median survival time was 2.43 years. The cumulative 1-, 3-, 5-, 7-, and 10 year survival rates were 76.70\%, 39.25\%, 26.50\%, 16.60\% and 3.56\%, respectively. After adjustment, female gender, ages 50-59 and $\geq 60$ years, tumour stage III+IV, a signet-ring cell carcinoma, and poor differentiation had significant associations with increased risk of CRC death. While the XRCC1 Arg/Arg homozygote appeared to be a risk factor for CRC death, the association was not significant. Conclusions: The genetic variant in the XRCC1 may not be associated with the survival of CRC patients in Thailand. Further studies are needed to verify our findings.
\end{abstract}

Keywords: XRCC1 polymorphism - survival - colorectal cancer - Thailand

Asian Pac J Cancer Prev, 17 (4), 2055-2060

\section{Introduction}

Colorectal cancer (CRC) is the third-most common cancer in the world, and in 2012 there were estimated to have been more than 746,298 newly diagnosed cases and more than 373,639 deaths due to the disease globally (Ferlay et al., 2015). In Europe and the United States of America the colorectal incidence rates are trending down (Rahib et al., 2014; Malvezzi et al., 2015), but in Asia the rates are trending up (Pourhoseingholi, 2012). This is also the case in Thailand where CRC is the fifth most common of all malignant tumors, and the age-standardized incidence rates (ASR) are estimated to be 15.2 per 100,000 for males and 10.1 per 100,000 for females (Khuhaprema \& Srivatanakul, 2008; Ferlay et al., 2015).

It is known that CRC is a multifactorial disease, which involves predispositional and environmental factors. While the eating of vegetables and fruit is a protective factor, the consumption of raw or over-cooked red meat, drinking alcohol, smoking and lack of physical activity are risk factors, particularly when there is a defective DNA repair gene. The X-ray repair cross-complementary protein 1 (XRCC1) is a single nucleotide polymorphism (SNP) which was initially discovered through its role in the repair of DNA damage caused by ionizing radiation (Brem and Hall, 2005). However, SNPs in XRCC1 may impair the efficiency of $\boldsymbol{X} \boldsymbol{R C C 1}$ in DNA repair activity, especially in base excision repair (BER) and singlestrand break repair processes. The presence of a SNP in $\boldsymbol{X} \boldsymbol{R C C 1}$ is also relevant to cancer (Shen et al., 2011). The polymorphisms of the $\boldsymbol{X R C C} \mathbf{1}$ gene in humans consist of Arg 194Trp, Arg280His and Arg399Gln. Many studies have suggested that $\boldsymbol{X} \boldsymbol{R} \boldsymbol{C C} \mathbf{C}$ Arg399Gln is associated with either increased or decreased risk for several types of cancers (Goode et al., 2002; Zhou et al., 2003; Yi et al., 2013), and $\boldsymbol{X R C C 1} \mathrm{Arg} 399 \mathrm{Gln}$ has been shown to increase the risk for CRC (Yeh et al., 2007; Kabziski et al., 2010; Yin et al., 2012; Zeng et al., 2012; Tian et

${ }^{1}$ Epidemiology and Biostatistics Section, Faculty of Public Health, ${ }^{2}$ Cancer Unit, Faculty of Medicine, ${ }^{4}$ Department of Paediatrics, Faculty of Medicine, ${ }^{5}$ ASEAN Cancer Epidemiology and Prevention Research Group, Khon Kaen University, Khon Kaen, ${ }^{3}$ Program of Public Health, Department of Applied Science, Faculty of Science and Technology, Loei Rajabhat University, Thailand *For correspondence: supannee@kku.ac.th 
al., 2013; Poomphakwaen et al., 2014; Dai et al., 2015). Differences in survival rates in CRC depend on factors called clinicopathological characteristics; these comprise tumor site, stage of the disease (TNM, Dukes' staging system), histological type, histological grading, type of treatment and sites of any metastases site (Elsaleh et al., 2000; Laohavinij, Maneechavakajorn \& Techatanol, 2010; Zhang et al., 2010).

While the potential association of $X \boldsymbol{R C C 1}$ polymorphisms with survival has been studied in a variety of cancers (Yoon et al., 2005; Bewick et al., 2006; Liu et al., 2007; Miao et al., 2012; Putthanachote et al., 2014), only a few studies have investigated the association

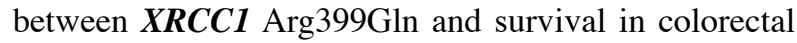
cancer, and the results of these remain controversial. In addition, no study has been published about the role of XRCC1 polymorphisms in CRC survival among Thai people.

The purpose of this study was to investigate the association between $\boldsymbol{X R C C 1}$ Gene polymorphisms and colorectal cancer survival in a Thai population.

\section{Materials and Methods}

\section{Subjects and data collection}

This is a retrospective cohort study in which the subjects were a consecutive series of newly diagnosed CRC patients admitted during the period from October, 2002, to October, 2006, to Srinagarind Hospital, the main teaching facility of the Faculty of Medicine, Khon Kaen University, and to Khon Kaen Regional Hospital. All had been diagnosed in accordance with the International Classification of Diseases for Oncology (ICD-O, $3^{\text {rd }}$ edition, 1st revision), and all diagnoses were histologically confirmed.

When CRC cases with multiple primary malignant tumors were excluded, 255 patients were recruited, and all were followed up until death or the end of the study (31 October, 2014). Survival time was defined as the time elapsing between diagnosis and either death or the end the study. Information about prognostic factors known from previous studies to be related to the CRC patients was retrieved from medical records; these prognostic factors were age at diagnosis, gender, tumor site, stage of the disease (TNM, Dukes' staging system), histological type, histological grading, and type of treatment. The $X \boldsymbol{R} C \boldsymbol{C} 1$ genotypes were retrieved from laboratory records (laboratory procedures described below).

The vital status of each patient was monitored from medical records and by linkage with the death registry of the Thai national statistics database.

\section{Laboratory methods}

Whole blood samples (3-5ml) were taken from all the recruited CRC patients, and these were centrifuged at $3,000 \mathrm{rpm}$ for 15 minutes to separate plasma, buffy coat and red blood cells. All specimens were kept at $-20^{\circ} \mathrm{C}$ at the Cancer Unit in the Faculty of Medicine, Khon Kaen University. The genomic DNA was extracted from the buffy coat at Nagoya City University Medical School, Japan.
PCR amplification and detection of genetic polymorphisms

A real-time polymerase chain reaction with high resolution melting technique (Real-time PCR-HRM) was performed in order to identify the $\boldsymbol{X} \boldsymbol{R} \boldsymbol{C} \boldsymbol{C} \boldsymbol{1}$ polymorphisms. DNA amplification was performed in a 96-well plate in a LightCycler ${ }^{\circledR} 480$ Real-Time PCR System. The amplification of $\boldsymbol{X R C C 1}$ Gln399Arg gene used two primers, forward: 5'- AGT GGG TGC TGG ACT GTC3 ' and reverse:5'- TTG CCC AGC ACA GGA TAA-3 '. The HRM data were analyzed using the LightCycler® 480 Gene Scanning software version 1.5 (Roche) in the Department of Microbiology, Faculty of Medicine, Khon Kaen University. To assess and validate genotyping quality, a PCR-restriction fragment length polymorphism analysis (PCR-RFLP) was performed in approximately $10 \%$ of random samples.

\section{Statistical analysis}

Categorical data were reported as numbers and percentages, and continuous data were summarised in the form of means with standard deviations or medians with ranges (minimum : maximum). Observed survival rates were calculated from a Kaplan-Meier survival curve, and the rates were presented as percentages of patients who were alive after a certain period of time with $95 \%$ confidence intervals (95\% CIs).

The log-rank test was used to compare the survival distributions in two or more groups. The associations between survival and the various prognostic factors were analysed using Cox proportional hazard regression models with the results reported in terms of crude and adjusted hazard ratios (HRadj) and their 95\%CIs. Factors reaching a $p<0.25$ level of significance in the univariate analysis in the initial model and other factors found to have significant association with CRC survival in previous studies were included as candidate variables a multivariate analysis using backward elimination.

All analyses were conducted using Stata version 10.0 (Stata Corp LP, 2007). Except for the process of selecting variables to be included in the multivariate analysis, statistical significance was set as $\mathrm{p}<0.05$.

\section{Ethical Consideration}

The study was approved by the Khon Kaen University Ethics Committee for Human Research (reference number: HE581400).

\section{Results}

\section{Characteristics of CRC patients}

The general and pathological characteristics of the 255 CRC patients are summarised in Table 1 . Most of the cases were males, and the median age was 55 years. The most common tumor site, stage and treatments were the colon (NOS), stage III, and surgery, respectively. By far the most frequently reported histological type of malignancy was adenocarcinoma, and for most patients the tumor cells were graded as well-differentiated. Regarding the prevalence of $\boldsymbol{X} \boldsymbol{R} \boldsymbol{C C} \boldsymbol{1}$ polymorphisms, Arg/Arg were found slightly more often than Gln/Arg. 
Table 1. Distribution of Demographic and Pathological Characteristics of Colorectal Cancer Patients

\begin{tabular}{|c|c|c|}
\hline Variables & Number(255) & $\%$ \\
\hline \multicolumn{3}{|l|}{ Gender } \\
\hline Male & 136 & 53.33 \\
\hline Female & 119 & 46.67 \\
\hline \multicolumn{3}{|l|}{ Age(years) } \\
\hline$<50$ & 93 & 36.47 \\
\hline $50-59$ & 75 & 29.41 \\
\hline$\geq 60$ & 87 & 34.12 \\
\hline Median (Min:Max) & $55(26: 75)$ & \\
\hline \multicolumn{3}{|l|}{ Tumour site } \\
\hline Cecum & 11 & 4.31 \\
\hline Appendix & 1 & 0.39 \\
\hline Ascending colon & 9 & 3.53 \\
\hline Hepatic flexure of colon & 6 & 2.35 \\
\hline Transverse colon & 4 & 1.57 \\
\hline Splenic flexure of colon & 3 & 1.18 \\
\hline Descending & 8 & 3.14 \\
\hline Sigmoid colon & 37 & 14.51 \\
\hline Overlapping lesion of colon & 1 & 0.39 \\
\hline Colon, NOS & 54 & 21.18 \\
\hline Rectosigmoid junction & 29 & 11.37 \\
\hline Rectum, NOS & 92 & 36.08 \\
\hline \multicolumn{3}{|l|}{ Stage of deisease } \\
\hline Stage I & 27 & 10.59 \\
\hline Stage II & 42 & 16.47 \\
\hline Stage III & 78 & 30.59 \\
\hline Stage IV & 77 & 30.2 \\
\hline Unknown stage & 31 & 12.16 \\
\hline \multicolumn{3}{|l|}{ Histological type } \\
\hline Adenocarcinoma & 237 & 92.94 \\
\hline Mucinous adenocarcinoma & 6 & 2.35 \\
\hline Signet-ring carcinoma & 12 & 4.71 \\
\hline \multicolumn{3}{|l|}{ Histological grading } \\
\hline Well differentiated Grade & 159 & 62.35 \\
\hline Moderately differentiated & 56 & 21.96 \\
\hline Poorly differentiated & 40 & 15.69 \\
\hline \multicolumn{3}{|l|}{ XRCC1 G399A genotype } \\
\hline Arg/Arg & 119 & 46.67 \\
\hline $\mathrm{G} \ln / \mathrm{Arg}$ & 106 & 41.57 \\
\hline $\mathrm{G} \ln / \mathrm{Gln}$ & 30 & 11.76 \\
\hline \multicolumn{3}{|l|}{ Types of treatment } \\
\hline Surgery only & 53 & 20.78 \\
\hline Radiation only & 2 & 0.78 \\
\hline Chemotherapy only & 4 & 1.57 \\
\hline Supportive treatment only & 21 & 8.24 \\
\hline Combined treatment & 175 & 68.62 \\
\hline Combined treatment* & Number (153) & \\
\hline $\mathrm{S}+\mathrm{C} / \mathrm{R}$ & 129 & 84.31 \\
\hline $\mathrm{S}+\mathrm{R}+\mathrm{C}$ & 24 & 15.69 \\
\hline
\end{tabular}

*exclude patients who acquired supportive care; S, Surgery; C, Chemotherapy; R, Radiotherapy

\section{Survival rate of $C R C$ patients}

For the 255 CRC cases, the overall follow-up persontime was 570 person-years, and the overall mortality rate was 28 per 100 person-years ( $95 \% \mathrm{CI}=24.17$ to 32.92$)$. The cumulative 1-,3-,5-,7-, and 10 years survival rates were $76.70 \%, 39.25 \%, 26.50 \%, 16.60 \%$ and $3.56 \%$, respectively (Table 2). Figure 1 shows the median survival time of all CRC patients, which was 2.43 years (95\% CI: 1.88 to 2.83 ). The survival times by stage of disease, histological type and $\boldsymbol{X} \boldsymbol{R C C 1}$ polymorphisms are presented in Figures 2-4. When the stages were
Table 2. Survival Rate of Colorectal Cancer Patients After Diagnosis

\begin{tabular}{lcc}
\hline Survival time & Survival rate $(\%)$ & $95 \%$ CI \\
\hline 1 year & 76.70 & $70.61-81.70$ \\
3 years & 39.25 & $32.36-46.07$ \\
5 years & 26.50 & $19.87-33.58$ \\
7 years & 16.60 & $10.51-23.90$ \\
10 years & 3.56 & $0.74-10.32$ \\
\hline
\end{tabular}

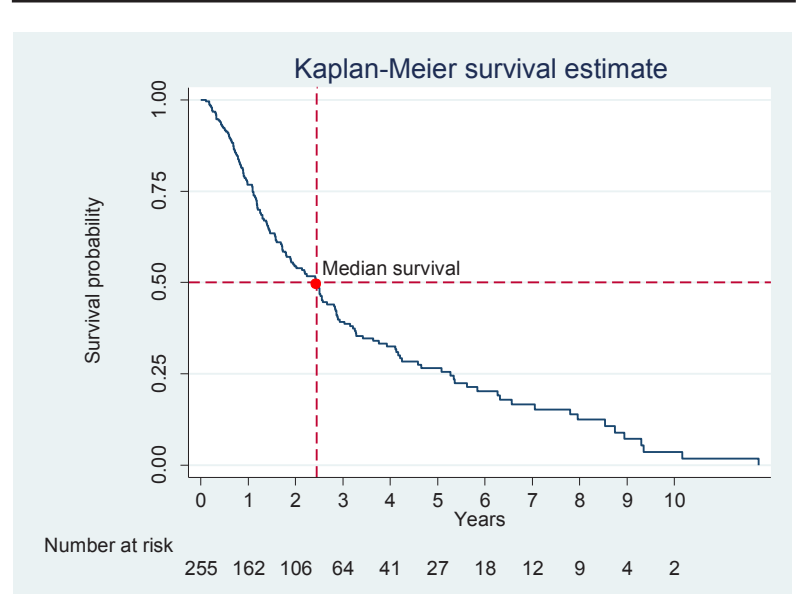

Figure 1. Overall Survival Curve of Colorectal Cancer

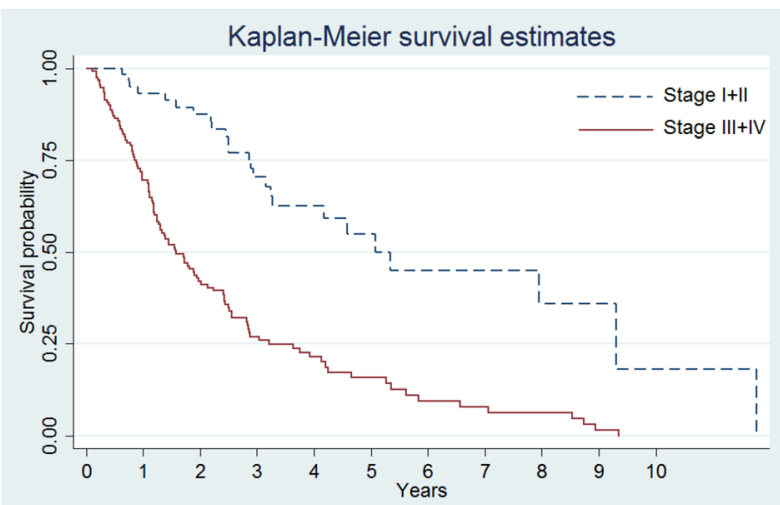

Figure 2. Survival Curve of Colorectal Cancer by Stage of Disease

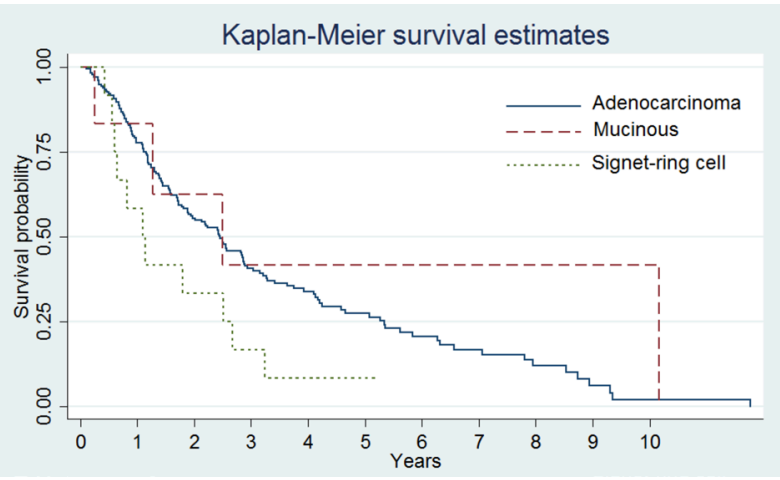

Figure 3. Survival Curve of Colorectal Cancer by Histological type

grouped as stage I+II and stage III+IV, the median survival times were 5.08 years and 1.57 years, respectively. The median survival times for the histological types of adenocarcinoma, mucinous and signet-ring cell were 2.45 , 2.50 and 1.09 years, respectively. The median survival times for patients with the Arg/Arg, Gln/Arg and Gln/ 


\begin{tabular}{|c|c|c|c|c|c|}
\hline Variable & Number $(\%)$ & $\begin{array}{c}\text { Median time } \\
\text { (Months) } 95 \% \text { CI }\end{array}$ & $\begin{array}{l}\text { Crude HR } \\
(95 \% \mathrm{CI})\end{array}$ & $\begin{array}{c}\text { Adjusted HR } \\
(95 \% \mathrm{CI})\end{array}$ & p-value \\
\hline Gender & & & & & 0.005 \\
\hline Female & $119(46.7)$ & $1.56(1.20-2.23)$ & 1 & 1 & \\
\hline Male & $136(53.3)$ & $2.86(2.45-3.75)$ & $0.59(0.43-0.82)$ & $0.58(0.40-0.85)$ & \\
\hline Age (years) & & & & & 0.017 \\
\hline$<50$ & $93(36.5)$ & $2.54(1.90-3.92)$ & 1 & 1 & \\
\hline $50-59$ & $75(20.4)$ & $2.01(1.55-3.20)$ & $1.20(0.80-1.79)$ & $1.91(1.19-3.06)$ & \\
\hline$\geq 60$ & $87(34.1)$ & $1.97(1.30-2.89)$ & $1.47(1.01-2.14)$ & $1.59(1.01-2.51)$ & \\
\hline Tumor site & & & & & - \\
\hline Colon & $163(64.0)$ & $2.49(1.88-2.86)$ & 1 & - & \\
\hline Rectum & $92(36.0)$ & $2.40(1.29-2.88)$ & $1.03(0.74-1.43)$ & - & \\
\hline Stage of disease & & & & & $<0.001$ \\
\hline Stage I+II & $69(30.8)$ & $5.08(3.24-9.30)$ & 1 & 1 & \\
\hline Stage III+IV & $155(69.2)$ & $1.57(1.24-2.01)$ & $3.54(2.27-5.53)$ & $3.17(1.99-5.05)$ & \\
\hline Histological type & & & & & 0.081 \\
\hline Adenocarcinoma & $237(93.0)$ & $2.45(1.89-2.86)$ & 1 & 1 & \\
\hline Mucinous adenocarcinoma & $6(2.3)$ & $2.50(0.25-\mathrm{NA})$ & $0.65(0.23-1.82)$ & $2.14(0.66-6.98)$ & \\
\hline Signet-ring carcinoma & $12(4.7)$ & $1.09(0.55-2.66)$ & $2.00(1.10-3.70)$ & $2.47(1.08-5.62)$ & \\
\hline Histological grading & & & & & 0.066 \\
\hline Well differentiated Grade & $159(62.4)$ & $2.54(2.18-3.26)$ & 1 & 1 & \\
\hline Moderately differentiated & $56(22.0)$ & $1.90(1.30-3.20)$ & $1.14(0.77-1.68)$ & $1.32(0.85-2.06)$ & \\
\hline Poorly differentiated & $40(15.6)$ & $1.16(0.77-2.42)$ & $2.18(1.43-3.34)$ & $1.74(1.07-2.80)$ & \\
\hline XRCC1 G399A genotype & & & & & 0.23 \\
\hline Arg/Arg & $119(46.6)$ & $2.20(1.60-2.81)$ & 1 & 1 & \\
\hline Gln/Arg & $106(41.6)$ & $2.55(1.58-3.75)$ & $0.87(0.62-1.22)$ & $0.87(0.60-1.27)$ & \\
\hline $\mathrm{G} \ln / \mathrm{G} \ln$ & $30(11.8)$ & $2.67(1.56-6.31)$ & $0.71(0.43-1.20)$ & $0.58(0.31-1.11)$ & \\
\hline Types of treatment & & & & & 0.127 \\
\hline Surgery & $224(87.8)$ & $2.50(2.01-2.89)$ & 1 & 1 & \\
\hline Non-surgery & $31(12.2)$ & $0.83(0.58-1.10)$ & $2.37(1.52-3.67)$ & $1.52(0.89-2.58)$ & \\
\hline Combined treatment $*$ & Number (201) & & & & - \\
\hline Surgery only & $53(26.4)$ & $2.89(2.18-5.33)$ & 1 & - & \\
\hline $\mathrm{S}+\mathrm{C}$ & $124(61.7)$ & $2.13(1.70-2.83)$ & $1.39(0.90-2.16)$ & - & \\
\hline $\mathrm{S}+\mathrm{C}+\mathrm{R}$ & $24(11.9)$ & $2.50(1.33-3.75)$ & $1.37(0.68-2.77)$ & - & \\
\hline
\end{tabular}

*exclude patients who acquired supportive care; S, Surgery; C, Chemotherapy; R, Radiotherapy; p-value from Partial likelihood ratio test

\begin{tabular}{|c|c|c|c|}
\hline Variable & Adjusted HR & $95 \% \mathrm{CI}$ & $\mathrm{p}$-value \\
\hline Gender & & & 0.007 \\
\hline Female & 1 & & \\
\hline Male & 0.60 & $0.41-0.87$ & \\
\hline Age(years) & & & 0.004 \\
\hline$<50$ & 1 & & \\
\hline $50-59$ & 1.99 & $1.25-3.18$ & \\
\hline$\geq 60$ & 1.78 & $1.17-2.72$ & \\
\hline Stage of disease & & & $<0.001$ \\
\hline Stage I+II & 1 & & \\
\hline Stage III+IV & 3.32 & $2.09-5.27$ & \\
\hline Histological type & & & 0.08 \\
\hline Adenocarcinoma & 1 & & \\
\hline Mucinous adenocarcinoma & 2.01 & $0.62-6.52$ & \\
\hline Signet-ring carcinoma & 2.55 & $1.12-5.80$ & \\
\hline Histological grading & & & 0.024 \\
\hline Well differentiated Grade & 1 & & \\
\hline Moderately differentiated & 1.41 & $0.91-2.17$ & \\
\hline Poorly differentiated & 1.86 & $1.16-2.98$ & \\
\hline XRCC1 G399A genotype & & & 0.253 \\
\hline Arg/Arg & 1 & & \\
\hline Gln/Arg & 0.85 & $0.59-1.24$ & \\
\hline Gln/Gln & 0.60 & $0.32-1.14$ & \\
\hline
\end{tabular}

*p-value from partial likelihood ratio test

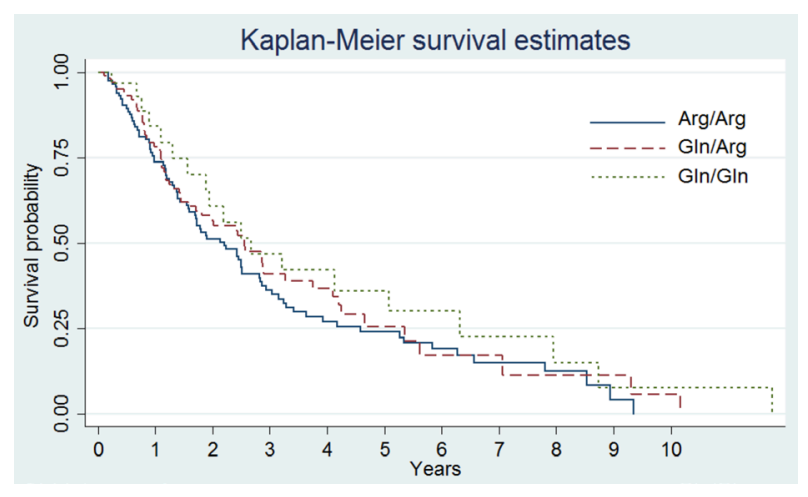

Figure 4. Survival Curve of Colorectal Cancer by XRCC1 Gene

Gln polymorphisms were $2.20,2.55$, and 2.67 years, respectively.

\section{Factors associated with survival}

The results of the initial model which included type of treatment (surgical vs. non-surgical) are shown in Table 3. In the multivariate analysis, male gender was found to have a statistically significant association with better survival $(\mathrm{HRadj}=0.58 ; 95 \% \mathrm{CI}=0.40-0.85)$, and three factors were found to have a statistically significant 
association with poorer survival: age 50-59 years (HRadj=1.91; 95\%CI=1.19-3.06), age 60 years or more $(\mathrm{HRadj}=1.59 ; 95 \% \mathrm{CI}=1.01-2.51)$, and late stage of disease (stages III and IV) (HRadj=3.17; 95\% CI=1.99-5.05). In the final model the treatment variable was excluded from the multivariate analysis, and the results are shown in Table 4. Male gender remained significantly associated with better survival (HRadj=0.60; 95\%CI $=0.41-0.87$ ) and the two older age groups were still significantly associated with poorer survival (for age 50-59 years: HRadj $=1.99 ; 95 \% \mathrm{CI}=1.25-3.18$. and for age 60 years or more: HRadj=1.78; 95\% CI=1.17-2.72). Late stage also remained significantly associated with poorer survival (HRadj=3.32; 95\%CI=2.09-5.27). However, there were now two additional factors associated with a worse prognosis: the presence of signet ring cells $((\mathrm{HRadj}=2.55$; 95\% CI $=1.12-5.80)$ and poor differentiation ( $\mathrm{HRadj}=1.86$; 95\% CI=1.16-2.98). The $\boldsymbol{X} \boldsymbol{R C C} \boldsymbol{1}$ polymorphisms were not associated with survival in either the initial or final multivariate analyses.

\section{Discussion}

In Asia, including Thailand, the incidence of CRC has dramatically increased in recent years. The main objective of this study was to investigate the association between $\boldsymbol{X R C C 1}$ gene polymorphism and CRC survival in Thailand, and this is the first analytic study to explore features of $\boldsymbol{X R C C 1}$ gene polymorphisms as possible death factors in a Thai population of CRC patients.

Our findings indicate that the $\boldsymbol{X} \boldsymbol{R} \boldsymbol{C C 1}$ polymorphisms of $\mathrm{Arg} / \mathrm{Arg}, \mathrm{Gln} / \mathrm{Arg}$ and $\mathrm{Gln} / \mathrm{Gln}$ have no association with survival of CRC patients. This is consistent with the conclusions of studies in Germany and Korea (Grimminger et al., 2010; Kim et al., 2010). It also in line with another study in Thailand which found that the genetic variant Gln339Arg in $\mathbf{X} \boldsymbol{R C C} \mathbf{1}$ made no statistically significant contribution to risk of death among Thai patients with stomach cancer (Putthanachote et al., 2014). However, there are differences in physiology and anatomy, environmental carcinogens, genetic mechanisms, and prognosis between the three segments of the bowel: the proximal and distal colon and the rectum (Li \& Lai, 2009). For example, a study in Taiwan, explored differences in survival between colon and rectal cancers in terms of


patients with $\boldsymbol{X R C C 1} \mathrm{Arg} / \mathrm{Gln}+\mathrm{Gln} / \mathrm{Gln}$ appeared to be at less risk of rectal cancer death when compared with patients who had Arg/Arg. In contrast, colon cancer patients with $\boldsymbol{X} \boldsymbol{R C C 1} \mathrm{Arg} / \mathrm{Gln}+\mathrm{Gln} / \mathrm{Gln}$ appeared to be at greater risk of colon cancer death when compared with patients who have Arg/Arg. These findings were not statistically significant, but they raise important issues about potential differences due to CRC site (Lai et al., 2013).

Normally, it is male gender which is associated with an increased risk of CRC death (for example, the Japanese study by Watanabe et al., 2001). However, in our study, female patients were at higher risk of CRC death than males; one possible explanation for this is that more of the female patients $(77.06 \%)$ were at late stages of the disease (stages III+IV) than were the males $(61.74 \%)$. This finding was supported by a Saudi Arabian study, but only for rectal cancer (Al-Ahwal et al., 2013). Not surprisingly, we found ages 50-59 and $\geq 60$ years, tumor stage III+IV, a signet-ring cell carcinoma, and poor differentiation had a significant association with increased risk of CRC death. Similar findings have been previously reported worldwide (Halvorsen and Seim, 1989; Jen et al., 1994; Takebayashi, Aklyama, Yamada, Akiba, \& Aikou, 1996; Dignam et al., 2003; Koo et al., 2008; Schetter, Leung S, Sohn et al,, 2008; Laohavinij, Maneechavakajorn \& Techatanol, 2010; Nitsche et al., 2013). It is noted that the finding regarding the signet ring cell carcinoma arose despite the fact that this histological type is less common than adenocarcinoma (O'Connell et al., 2004).

The 5-year survival rate of CRC patients in our study was $26.50 \%$. This rate was lower than that found in previous studies reported in Thailand. In 1995 and 2010, (Sriamporn et al., 1995; Laohavinij et al., 2010) the reported 5-year survival rates for CRC patients were $36.8 \%$ and $38.6 \%$, respectively, and another study (Berberoglu U, 2004) reported that the 5-year survival was even higher (62\%). Our 5-year survival rate is probably low because we obtained data from a tertiary hospital where most of patients were at late stages. Moreover, all the CRC cases in our study were confirmed histologically which means that other conditions with better prognoses were excluded.

Our study did have some limitations. Due to budget and time constraints, we studied only the effect of $\boldsymbol{X R C C I}$ Arg399Gln on survival of CRC patients, and this gene is only one type of the various components in the DNA repair process.

In conclusion, while gender, age, stages of disease, histological type (signet-ring cell) and histological grading (poorly differentiated) were factors affecting survival of CRC in a Thai population, no significant differences were founded in the effect of $\boldsymbol{X} \boldsymbol{R} \boldsymbol{C C 1} \mathrm{Arg} 399 \mathrm{Gln}$ polymorphisms on CRC survival. There is, however, a need for further research to confirm our findings, investigate related issues and explore differences and possible interactions in the way which $\boldsymbol{X} \boldsymbol{R C C 1}$ polymorphisms affect CRC survival between the three different segments of the bowel.

\section{Acknowledgements}

The authors would like to acknowledge MONKASHO for its initial support at the first phase of the project and Professor Tokudome for initiating the International collaborative epidemiological study. We also wish to thank Peechanika Chopjitt for the laboratory analyses and Peter Bradshaw for his advice and assistance in writing this paper.

\section{References}

Al-Ahwal MS, Shafik YH, Al-Ahwal HM (2013). First national survival data for colorectal cancer among Saudis between 1994 and 2004: what's next? BMC Public Health, 13, 73.

Berberoglu U (2004). Prognostic significance of total lymph node number in patients with T1-4N0M0 colorectal cancer. 
Hepato-Gastroenterol, 51, 1689-93.

Bewick MA, Conlon MSC, Lafrenie RM (2006). Polymorphisms in XRCC1, XRCC3, and CCND1 and Survival After Treatment for Metastatic Breast Cancer. J Clin Oncol, 24, 5645-51.

Brem R, Hall J (2005). XRCC1 is required for DNA single-strand break repair in human cells. Nucleic Acids Res. 3, 2512-20.

Dai Q, Luo H, Li XP, et al (2015). XRCC1 and ERCC1 polymorphisms are related to susceptibility and survival of colorectal cancer in the Chinese population. Mutagenesis:geu088.

Dignam JJ, Ye Y, Colangelo L, et al (2003). Prognosis after rectal cancer in blacks and whites participating in adjuvant therapy randomized Trials. J Clin Oncol, 21, 413-20.

Elsaleh H, Joseph D, Grieu F, et al (2000). Association of tumour site and sex with survival benefit from adjuvant chemotherapy in colorectal cancer. Lancet, 355, 1745-50.

Ferlay J, Soerjomataram I, Dikshit R, et al (2015). Cancer incidence and mortality worldwide: Sources, methods and major patterns in GLOBOCAN 2012. Int J Cancer, 136, 359-86.

Goode EL, Ulrich CM, Potter JD (2002). Polymorphisms in DNA repair genes and associations with cancer risk. Cancer Epidemiology Biomarkers Prevent, 11, 1513-30.

Grimminger PP, Brabender J, Warnecke-Eberz U, et al (2010). XRCC1 Gene polymorphism for prediction of response and prognosis in the multimodality therapy of patients with locally advanced rectal cancer. J Surgical Res, 164, 61-6.

Halvorsen TB, Seim E (1989). Association between invasiveness, inflammatory reaction, desmoplasia and survival in colorectal cancer. J Clinical Pathol, 42, 162-6.

Kabziński J, Przybyłowska K, Mik M, et al (2010). An Association of ARG399GLN Polymorphism of XRCC1 gene with a risk of colorectal cancer. Polish J Surg, 82, 677-680.

Khuhaprema T, Srivatanakul P (2008). Colon and rectum cancer in Thailand: an overview. Japanese J Clin Oncol, 38, 237-43.

Kim JG, Chae YS, Sohn SK, et al (2010). IVS10+12A>G polymorphism in hMSH2 gene associated with prognosis for patients with colorectal cancer. Ann Oncol, 21, 525-9.

Koo JH, Jalaludin B, Wong SKC, et al (2008). Improved survival in young women with colorectal cancer. Am J Gastroenterol, 103, 1488-95.

Lai CY, Hsieh LL, Sung FC, et al (2013). Tumor site- and stagespecific associations between allelic variants of glutathione s-transferase and DNA-repair genes and overall survival in colorectal cancer patients receiving 5-fluorouracil-based chemotherapy. PLOS ONE, 8, e69039.

Laohavinij S, Maneechavakajorn J, Techatanol P (2010). Prognostic factors for survival in colorectal cancer patients. J Med Associat Thailand Chotmaihet Thangphaet, 93, 1156-66.

Li F, Lai M (2009). Colorectal cancer, one entity or three. $J$ Zhejiang University Science B, 10, 219-29.

Liu B, Wei J, Zou Z, et al (2007). Polymorphism of XRCC1 predicts overall survival of gastric cancer patients receiving oxaliplatin-based chemotherapy in Chinese population. European J Human Genetics, 15, 1049-53.

Malvezzi M, Bertuccio P, Rosso T, et al (2015). European cancer mortality predictions for the year 2015: does lung cancer have the highest death rate in EU women? Ann Oncol, mdv001.

Miao J, Zhang X, Tang Q-L, Wang X-Y, Kai L (2012). Prediction value of XRCC 1 gene polymorphism on the survival of ovarian cancer treated by adjuvant chemotherapy. Asian Pac J Cancer Prev, 13, 5007-10.

Nitsche U, Zimmermann A, Spath C, et al (2013). Mucinous and signet-ring cell colorectal cancers differ from classical adenocarcinomas in tumor biology and prognosis. Ann Surg, 258, 775-83.

O'Connell JB, Maggard MA, Ko CY (2004). Colon cancer survival rates with the new american joint committee on cancer sixth edition staging. J National Cancer Institute 96, 1420-5.

Poomphakwaen K, Promthet S, Suwanrungruang K, et al (2014). XRCC1 gene polymorphism, diet and risk of colorectal cancer in Thailand. Asian Pac J Cancer Prevent, 15, 74797486.

Pourhoseingholi MA (2012). Increased burden of colorectal cancer in Asia. World J Gastrointestinal Oncol, 4, 68.

Putthanachote N, Promthet S, Suwanrungruan K, et al (2014). XRCC1 gene polymorphism, clinicopathological characteristics and stomach cancer survival in Thailand. Asian Pac J Cancer Prev, 16, 6111-6.

Rahib L, Smith BD, Aizenberg R, et al (2014). Projecting cancer incidence and deaths to 2030: the unexpected burden of thyroid, liver, and pancreas cancers in the United States. Cancer Res, 74, 2913-21.

Schetter AJ, Leung S, Sohn JJ, et al (2008). MIcrorna expression profiles associated with prognosis and therapeutic outcome in colon adenocarcinoma. JAMA, 299, 425-36.

Shen W, Chen H, Liu P (2011). XRCC1 polymorphisms and pancreatic cancer: a meta-analysis. Chinese J Cancer Res, 23, 165-70.

Sriamporn S, Black RJ, Sankaranarayanan R, et al (1995). Cancer survival in Khon Kaen province, Thailand. Int $J$ Cancer, 61, 296-300.

Takebayashi Y, Aklyama S, Yamada K, Akiba S, Aikou T (1996). Angiogenesis as an unfavorable prognostic factor in human colorectal carcinoma. Cancer, 78, 226-31.

Tian Z,Li Y-L,Liu J-G (2013). XRCC1 Arg399Gln polymorphism contributes to increased risk of colorectal cancer in Chinese population. Molecular Biology Reports, 40, 4147-51.

Watanabe T, Wu T-T, Catalano PJ, et al (2001). Molecular predictors of survival after adjuvant chemotherapy for colon cancer. New England J Med, 344,1196-1206.

Yeh C-C, Sung F-C, Tang R, Chang-Chieh CR, Hsieh LL (2007). Association between polymorphisms of biotransformation and DNA-repair genes and risk of colorectal cancer in Taiwan. J Biomedical Sci 14, 183-93.

Yi L, Xiao-feng H, Yun-tao L, et al (2013). Association between the XRCC1 Arg399gln polymorphism and risk of cancer: evidence from 297 case-control studies. PLOS ONE, 8, 78071.

Yin G, Morita M, Ohnaka K, et al (2012). Genetic polymorphisms of $X \boldsymbol{R C C 1}$, alcohol consumption, and the risk of colorectal cancer in Japan. J Epidemiol, 22, 64-71.

Yoon SM, Hong YC, Park HJ et al (2005). The polymorphism and haplotypes of $\boldsymbol{X R C C 1}$ and survival of non-small-cell lung cancer after radiotherapy. Int J Radiat Oncol Biology Physics, 63, 885-91.

Zeng FR, Ling Y, Yang J, et al (2012). X-ray repair crosscomplementing group 1 Arg399Gln gene polymorphism and susceptibility to colorectal cancer:a meta-analysis. Tumor Biol, 34, 555-563.

Zhang S, Gao F, Luo J, Yang J (2010). Prognostic factors in survival of colorectal cancer patients with synchronous liver metastasis. Colorectal Disease, 12, 754-61.

Zhou W, Liu G, Miller DP, et al (2003). Polymorphisms in the DNA repair genes $\boldsymbol{X} \boldsymbol{R} \boldsymbol{C C} 1$ and ERCC2, smoking, and lung cancer risk. Cancer Epidemiol Biomarkers Prevent, 12, 359-65. 